\title{
Topical Issue on Thermal Non-Equilibrium Phenomena in Soft Matter
}

\author{
Published online: 22 November 2019 - (c) EDP Sciences / Società Italiana di Fisica / Springer-Verlag GmbH
} Germany, part of Springer Nature, 2019

The investigation of soft matter under non-equilibrium conditions attracts intense scrutiny. External fields, e.g. magnetic or electrostatic can impart striking responses to soft matter, driving technological developments and new devices. Thermal fields do also induce a wide range of coupling effects that can be used to manipulate suspensions, solutions or pure fluids, by inducing mass and charge transport. The Ludwig-Soret and Seebeck effects [1-3] are important principles that are being used in the context of energy recovery applications, e.g., thermoelectrics [4], desalination or oil fractionation $[5,6]$. While the discovery of the thermodiffusion and thermoelectricity dates back to the mid 19th century, the investigation of these physical effects is witnessing a renaissance, which is being fuelled to some extent by: a) the development of high precision experimental techniques to measure thermophoretic drifts and thermodiffusion in complex mixtures accounting for gravity effects; b) theoretical methods that have enabled the discovery of novel thermal coupling phenomena and the interrogation of the microscopic mechanisms driving thermophoretic and thermodiffusive fluxes. These advances have driven the development of e.g. the microscale thermophesis [7] technique, which is being used commercially in the quantification of protein binding events.

This Topical Issue compiles articles highlighting the state-of-the-art on thermal non-equilibrium phenomena in soft matter, several of which draw on presentations made at the 13th International Meeting on Thermodiffusion (IMT13), held in London in September 2018. The articles cover a range of topics, such as, theory and simulations of multicomponent mixtures, non-equilibrium fluctuations in thermal fields, thermophoresis of colloidal suspensions, thermodiffusion in porous media, Soret-driven hydrodynamic instabilities and thermodiffusion under microgravity conditions.

Thermodiffussion in aqueous solutions is attracting considerable interest, given the complex thermophoretic and thermodiffusive response of ions, polymers and nanoparticles in water. Strong interest in aqueous solutions is partially driven by the development of microscale thermophoresis and by recent proposals regarding the role of thermal gradients in speeding up biochemical reactions involving RNA fragments that are relevant to the origin of life on Earth. The speed up of these reactions often requires additives such as 1-Ethyl-3-(3-dimethylaminopropyl)carbodiimide (EDC) and EDC-hydrochloride (EDC-HCl). Thermodiffusion experiments provide a route to quantify thermophoretic drifts and activation energies for hydrolysis [8] and dynamic behaviour of amino-acids [9].

Thermophobic (high-temperature) and thermophilic (low-temperature) responses, whose physical origin is still under debate, are widely observed in aqueous solutions. The possibility of inverting the thermophoretic response of colloids using different polar solvents (DMSO or water) is demonstrated in ref. [10]. Correlations between the hydrophilicity of polar compounds and the Soret coefficient have been established by using the infrared thermal diffusion forced Rayleigh scattering technique, and a connection between the temperature dependence of the Soret coefficient and the partition coefficient, $\log P$ has been reported [11].

Gravity is known to drive coupling effects in the presence of thermal gradients. This observation has motivated a number of studies to both understand the effect and to avoid it. International collaborations have crystallized around multiple microgravity experiments [12] in particular to measure Soret coefficients of multicomponent mixtures [13]. The results from these experiments are in good agreement with data of specific systems measured on Earth using two-color optical beam deflection and the thermogravitational column technique [14]. These experiments are important to identify the role of gravity, e.g. in the growth of non-equilibrium concentration fluctuations during a transient process, the stability of the separations obtained in thermogravitational devices $[15,16]$. Using a sufficiently fast camera, the coupling of viscous, thermal and mass relaxation modes has been demonstrated in ternary polymer solutions. A theory for the dynamics of non-equilibrium fluctuations in ternary solutions upon the effect of gravity has also been proposed [17]. 
Gravitational effects are also important in fractionation of gases in oil reservoirs and the combined impact of thermogravitational fields was explored using irreversible thermodynamic principles to increase the accuracy of models used by reservoirs engineers [18].

Further investigations of soft matter under thermal fields involve the exploration of thermodiffusion under acoustic streaming as a route to drive mass separation in binary fluids [19], the build up of non-linear regimes of Soret-driven convection in ternary fluids [20], the role of thermal mass transfer mechanisms in aqueous solutions relevant in heat exchangers [21], theoretical aspects involved in the thermoosmosis in pumping devices [22] or thermomechanical effects in anisotropic liquids, such as liquid crystals, with the possibility of measuring experimentally the coupling between the heat flux and torque driving the rotation of the liquid [23].

Computer simulations and theory are at the heart of the techniques needed to rationalize the complex set of experimental observations discussed above. The Faxén theorem has been used to obtain a new equation for the Soret coefficient of colloids, establishing correlations with the temperature derivative of the surface tension, viscosities and thermal conductivities of colloids and solvent [24]. Expressions for the thermophoretic mobility have been obtained using hydrodynamic reciprocal approaches, supporting the importance of interfacial transport on thermophoresis [25]. Two contributions illustrate the power of computer simulations to understand thermophoresis of protein-ligand systems [26], while the role of internal degrees of freedom in defining thermophoresis via the thermal orientation coupling effect has been demonstrated using non-equilibrium molecular dynamics simulations (NEMD) [27]. Furthermore, NEMD simulations were used to study fractionation of gases and oil in order to improve the model description of oil and gas reservoirs [28]. As the complexity of the investigated mixtures increases, having the correct definition of frame invariant thermodiffusion and Soret coefficients is essential. This has been addressed in ref. [29].

The summary above provides just a flavour of the key developments discussed in this Topical Issue.

We are very grateful to all the contributing authors, as well as the reviewers for their constructive criticisms. We thank the Editors-in-Chief, François Graner and Francesco Sciortino, for sharing our vision that thermal non-equilibrium effects in soft matter is a very relevant topic to the readership of The European Physical Journal E, and for accepting to publish this Topical Issue. Also, we want to express our gratitude to the Editorial Staff of The European Physical Journal E, who have offered us unconditional help, sharing their competence and time to efficiently handle the manuscripts.

Fernando Bresme, Velisa Vesovic, Henri Bataller, and Fabrizio Croccolo Guest Editors

\section{References}

1. C. Ludwig, Sitzber. Akad. Wiss. Wien, Math.-Naturwiss. Kl. 20, 539 (1856).

2. C. Soret, Arch. Sci. Phys. Nat. 2, 48 (1879).

3. T.J. Seebeck, Ann. Phys. 82, 253 (1826).

4. G.J. Snyder, E.S. Toberer, Nat. Mater. 7, 105 (2008).

5. A.M. Benneker, T. Rijnaarts, R.G. Lammertink, J.A. Wood, J. Membr. Sci. 548, 421 (2018).

6. G. Galliero, H. Bataller, F. Croccolo, R. Vermorel, P. Artola, B. Rousseau, V. Vesovic, M. Bou-Ali, J.M. Ortiz de Zárate, K. Zhang, F. Montel, Microgravity Sci. Technol. 28, 79 (2016).

7. C.J. Wienken, P. Baaske, U. Rothbauer, D. Braun, S. Duhr, Nat. Commun. 1, 100 (2010).

8. D. Niether, S. Wiegand, Eur. Phys. J. E 42, 117 (2019).

9. C.M. Romero, G.P. Trujillo, L.M.P. Verissimo, M.A. Esteso, M.L. Ramos, A.C.F. Ribeiro, Eur. Phys. J. E 42, 94 (2019).

10. M. Sarkar, J.C. Riedl, G. Demouchy, F. Gélébart, G. Mériguet, V. Peyre, E. Dubois, R. Perzynski, Eur. Phys. J. E 42, 72 (2019).

11. M. Bjelčič, D. Niether, S. Wiegand, Eur. Phys. J. E 42, 68 (2019).

12. M. Braibanti, P.-A. Artola, P. Baaske, H. Bataller, J.-P. Bazile, M.M. Bou-Ali, D.S. Cannell, M. Carpineti, R. Cerbino, F. Croccolo, J. Diaz, A. Donev, A. Errarte, J.M. Ezquerro, A. Frutos-Pastor, Q. Galand, G. Galliero, Y. Gaponenko, L. García-Fernández, J. Gavaldá, F. Giavazzi, M. Giglio, C. Giraudet, H. Hoang, E. Kufner, W. Köhler, E. Lapeira, A. Laverón-Simavilla, J.-C. Legros, I. Lizarraga, T. Lyubimova, S. Mazzoni, N. Melville, A. Mialdun, O. Minster, F. Montel, F.J. Molster, J.M. Ortiz de Zárate, J. Rodríguez, B. Rousseau, X. Ruiz, I.I. Ryzhkov, M. Schraml, V. Shevtsova, C.J. Takacs, T. Triller, S. Van Vaerenbergh, A. Vailati, A. Verga, R. Vermorel, V. Vesovic, V. Yasnou, S. Xu, D. Zapf, K. Zhang, Eur. Phys. J. E 42, 86 (2019).

13. A. Mialdun, H. Bataller, M.M. Bou-Ali, M. Braibanti, F. Croccolo, A. Errarte, J.M. Ezquerro, J.J. Fernández, Yu. Gaponenko, L. García-Fernández, J. Rodríguez, V. Shevtsova, Eur. Phys. J. E 42, 87 (2019).

14. T. Triller, D. Sommermann, M. Schraml, F. Sommer, E. Lapeira, M.M. Bou-Ali, W. Köhler, Eur. Phys. J. E 42, 27 (2019).

15. M. Carpineti, M. Sabato, F. Croccolo, A. Vailati, Eur. Phys. J. E 42, 25 (2019).

16. B. Seta, E. Lapeira, D. Dubert, F. Gavaldá, M.M. Bou-Ali, X. Ruiz, Eur. Phys. J. E 42, 58 (2019). 
17. L. García-Fernández, P. Fruton, H. Bataller, J.M. Ortiz de Zárate, F. Croccolo, Eur. Phys. J. E 42, 124 (2019).

18. F. Montel, H. Hoang, G. Galliero, Eur. Phys. J. E 42, 65 (2019).

19. M.C. Charrier-Mojtabi, X. Jacob, T. Dochy, A. Mojtabi, Eur. Phys. J. E 42, 64 (2019).

20. T.P. Lyubimova, S.A. Prokopev, Eur. Phys. J. E 42, 76 (2019).

21. P. Fernandez de Arroiabe, A. Martinez-Urrutia, X. Peña, M. Martinez-Agirre, M. Mounir Bou-Ali, Eur. Phys. J. E 42, 85 (2019).

22. S. Semenov, M. Schimpf, Eur. Phys. J. E 42, 141 (2019).

23. S. Bono, Y. Maruyama, K. Nishiyama, Y. Tabe, Eur. Phys. J. E 42, 99 (2019).

24. A. Arango-Restrepo, J.M. Rubi, Eur. Phys. J. E 42, 55 (2019).

25. J. Burelbach, H. Stark, Eur. Phys. J. E 42, 4 (2019).

26. J. Luettmer-Strathmann, Eur. Phys. J. E 42, 77 (2019).

27. O.R. Gittus, J.D. Olarte-Plata, F. Bresme, Eur. Phys. J. E 42, 90 (2019).

28. H. Hoang, P. Nguyen, M. Pujol, G. Galliero, Eur. Phys. J. E 42, 61 (2019).

29. J.M. Ortiz de Zárate, Eur. Phys. J. E 42, 43 (2019). 